\title{
Biogenesis of silver nanoparticles using leaf extracts of Asparagus racemosus and Sophora interrupta: structure characterization, antibacterial and anticancer studies
}

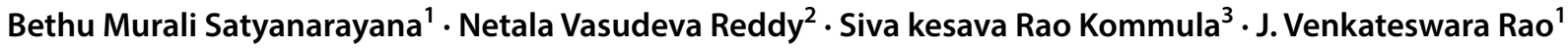

Received: 12 May 2020 / Accepted: 13 October 2020 / Published online: 21 October 2020

(c) Springer Nature Switzerland AG 2020

\begin{abstract}
The present investigation reports simple and eco-friendly biogenesis of silver nanoparticles (AgNPs) using leaf extracts of Asparagus racemosus and Sophora interrupta. UV-Vis spectra showed absorption peaks at 413 and $420 \mathrm{~nm}$ respectively corresponding to $A$. racemosus (AR-AgNPs) and S. interrupta (SI-AgNPs). TEM, DLS, XRD and TGA studies revealed that biogenic AgNPs are monodispersed, spherical shaped, thermally stable, FCC crystals and 4-15 nm in size. Zeta potential values were found to be -28.9 and $-18.6 \mathrm{mV}$ respectively corresponding to SI-AgNPs and AR-AgNPs. SI-AgNPs exhibited strong antibacterial activities against Escherichia coli, Klebsiella pneumoniae, Bacillus subtilis and Micrococcus luteus with inhibition zones of $11.8,10.5,9.8$ and $9.1 \mathrm{~mm}$ respectively. Further SI-AgNPs exhibited significant cytotoxic properties against SKOV3, DU149, PC3 and A549 cells with IC ${ }_{50}$ values of $120.87,191.34,235.06$ and $314.27 \mu \mathrm{g} / \mathrm{mL}$ respectively. SIAgNPs induce pronounced apoptotic effects on SKOV3 cells including loss of membrane integrity, chromatin condensation (pyknosis) and nuclear fragmentation (karyorrhexis). SI-AgNPs exhibited significant cell migration inhibition by reducing the wound healing of SKOV3 monolayers. Phytosynthesized AgNPs were found to be biocompatible towards normal $(\mathrm{CHO})$ cells.
\end{abstract}

Bethu Murali Sathyanarayana and Netala Vasudeva Reddy contributed equally to this work.

$\triangle$ Bethu Murali Satyanarayana, bmurali321@gmail.com | ${ }^{1}$ Applied Biology Division, CSIR-Indian Institute of Chemical Technology, Hyderabad, Telangana 500007, India. ²Department of Biotechnology, Sri Venkateswara University, Tirupati, Andhra Pradesh 517502 , India. ${ }^{3}$ Department of Biochemistry, Dr. Y.S.R. Horticultural University, Venkataramanna Gudem, Andhra Pradesh, India. 


\section{Graphic abstract}

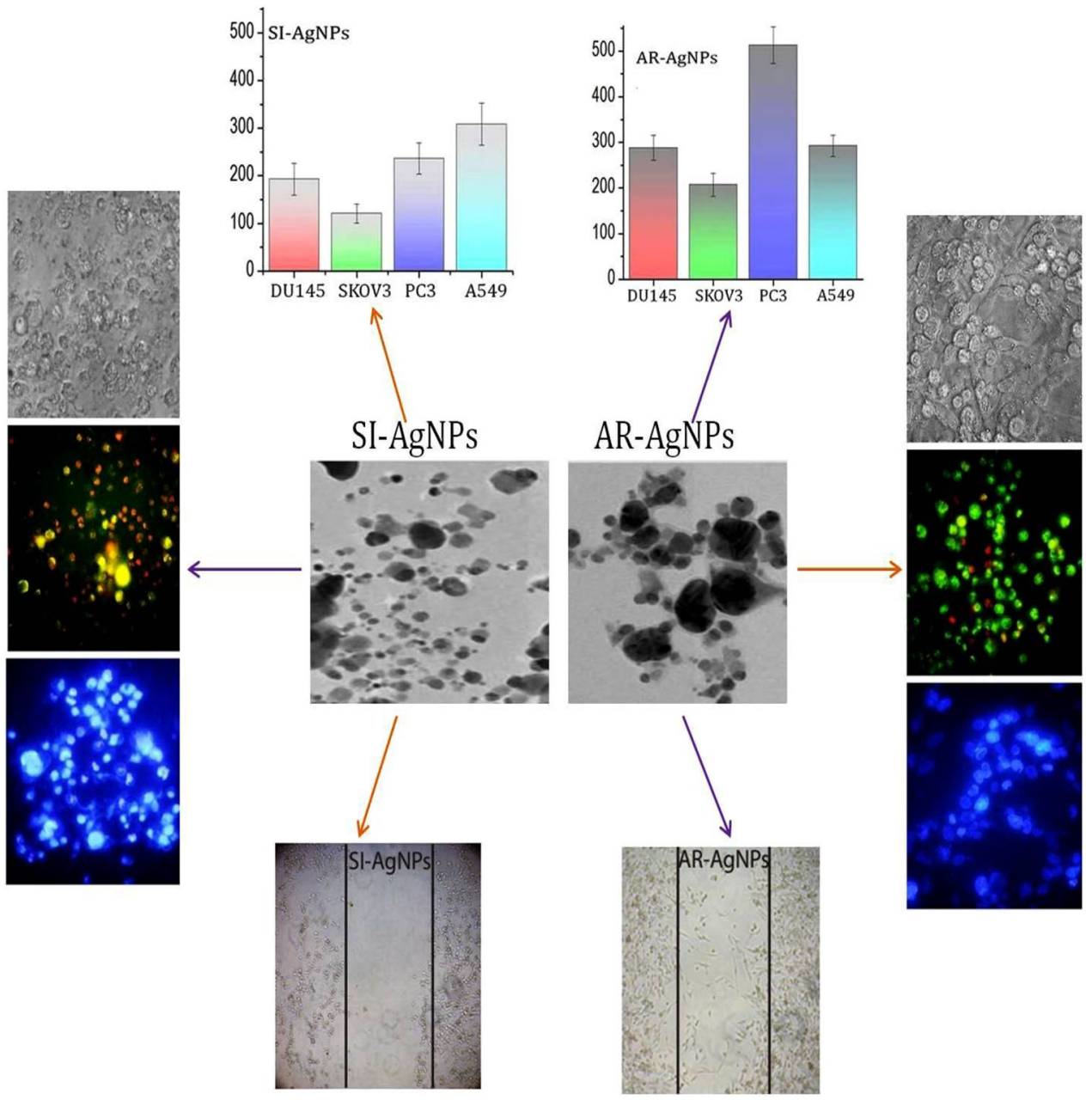

Keywords Silver nanoparticles - Sophora interrupta - Antibacterial activity - Anticancer activity - Apoptotic studies . Wound healing assay

\section{Introduction}

Nanotechnology has become one of the most emerging areas that intertwine all the fields of science including physics, chemistry, biology, medicine and material science [1]. Nanobiotechnology involves the eco-friendly synthesis and biomedical applications of different types of metal and metal oxide nanomaterials [2]. Metallic nanomaterials, particularly silver nanoparticles (AgNPs) have attracted global attention due to their unique physico-chemical and biological properties including optical, electronic, thermal, optoelectronic, catalytic, antimicrobial and cytotoxic properties [2-5]. Owing to their unique properties, AgNPs have been widely employed in the various applications including optical materials [4], sensors for the detection of different chemicals, ions, pollutants and pathogens $[6,7]$ catalysts for the chemical reactions and dyes [8], bioprobes for enzymes [9], bioimaging and drug delivery [10, 11] and bioactive agents including antimicrobial, antioxidant, and anticancer agents $[1-3,12,13]$. The unique properties of AgNPs are determined by their size, shape, crystalinity and stability [4]. Different physical, chemical and biological methods have been employed for the preparation of stable nanomaterials with controlled size and shape [14].

Different physical and chemical approaches have been reported for the preparation of AgNPs. Notable physical 
synthesis methods including laser ablation, gamma irradiation, electron irradiation and ultrasound irradiation methods [15] have been reported successfully. Different chemical synthesis methods including polyol synthesis, polyaniline synthesis, polyacrylate synthesis, polyethylene synthesis, sonochemical synthesis and reduction methods [15-18] have been widely employed for the preparation of AgNPs. Physical and chemical methods are time consuming and vast expensive. Further physical and chemically synthesized AgNPs are not clean and biocompatible as they involve toxic chemicals as coating/capping agents. Synthesizing AgNPs using plant extracts has been extensively studied and recognized as a green and efficient way for the synthesis of clean, non-toxic and biocompatible AgNPs $[19,20]$. Phytochemicals of plant extracts may act as reducing and capping agents for AgNPs. The reduction methods by plant extract containing enzymes/proteins, polyphenols, flavonoids, amino acids, polysaccharides, and vitamins are eco-benign, yet chemically complex [21]. The key advantages of plant mediated synthesis (phytosynthesis) of AgNPs includes simple, eco-friendly and rapid synthesis at ambient temperatures, neutral $\mathrm{pH}$, controlled size and shape characteristics, non-toxic, and increased biocompatibility [22]. Phytosynthesis of AgNPs is a bottom-up approach involving the reduction and oxidation reactions mediated by enzymes, proteins, flavonoids, polyphenols or other biomolecules with reducing properties. AgNPs have been synthesized successfully using different plant extracts including Salvinia molesta [3], Berberis vulgaris [12], Olax scandens [13], Punica granatum [19], ConvolvuIus arvensis [21], Morus alba [23], Tithonia diversifolia [24], Bauhinia acuminate [25], Phlomis bracteosa [26], Tanacetum vulgare [27], Ficus religiosa [28], Mangifera indica [29], Nyctanthes arbor [30], Priva cordifolia [31], Artocarpus heterophyllus [32].

Medicinal plants were collected from Seshachalam forest of Eastern Ghats, Andhra Pradesh India. The medicinal plants including Asparagus racemosus and Sophora interrupta which are abundantly available in this region and possess properties such as antibacterial, antifungal, antiinflammatory, analgesic, antidiabetic, antipyretic, antiseptic, antioxidant and anticancer properties. All these collected species were identified by the renowned plant taxonomist at Osmania University, Hyderabad, India.

Asparagus racemosus belongs to the family Asparagaceae is commonly known as shatavari/shatamull/pilli gaddalu in Telugu. The plant grows in both the tropical and subtropical areas of India. The plant contain woody stem with small spines. The plant flowers leaving a mild fragrance in its surroundings with attractive red berry fruits. The plant is used in traditional Indian medicine for the control of stomach pain, diarrhoea, inflammation, burning sensation, excessive perspiration, nervous debility, cough, bronchitis and skin diseases [33]. Sophora interrupta belongs to the family of Fabaceae and it has importance as a folk-lore medicine for preventing many ailments including cancer. It is popularly known as Adavi rela or Adavi billa in Telugu. This plant is traditionally used to treat different diseases of human health [34].

In the present study we investigate the preparation of AgNPs using leaf extracts of two plants including $A$. racemosus and $S$. interrupta collected from Seshachalam hills range of Eastern Ghats, India. The prepared biogenic AgNPs were characterized by using different spectroscopic techniques and compared the physico-chemical properties. Antibacterial properties of biogenic AgNPs were evaluated against Gram-positive and Gram-negative bacteria. Further anticancer properties of the biogenic AgNPs were evaluated against different human cancer cell lines as well as normal mammalian cells.

\section{Materials and methods}

\subsection{Chemicals, reagents and cell lines}

Two different cell culture media Dulbecco/Vogt modified Eagle's (Harry Eagle) minimal essential medium (DMEM), and Roswell Park Memorial Institute medium (RPMI-1640) were bought from Sigma-Aldrich (St. Louis, MO, USA). Fetal bovine serum was obtained from Gibco (Invitrogen), South America origin. PBS and HBSS were purchased from Sisco Research Laboratories Pvt. Ltd. (SRL)-India. Silver nitrate $\left(\mathrm{AgNO}_{3}\right)$ and all other chemicals were purchased from Sigma. The cell lines such as human ovarian carcinoma cells (SKOV3), human prostate cancer (DU145 and PC-3), human lung adenocarcinoma (A549) and Chinese hamster ovary $(\mathrm{CHO})$ cell lines were obtained from the National Centre for Cellular Sciences (NCCS), Pune, India.

\subsection{Preparation of leaf aqueous extracts}

The dried leaves of plant species including A. racemosus and S. interrupta were grounded into fine powder and then transferred into glass jars of $1 \mathrm{~L}$ capacity. Initially, $100 \mathrm{~g}$ of dried leaf powder was added to $200 \mathrm{~mL}$ of autoclaved Milli-Q water. The mixture was boiled for 2-3 times ( $3 \mathrm{~min}$ each) at 30 min interval using a microwave oven $(800 \mathrm{w}$, $L G)$. During each interval, the mixture was vigorously stirred. The mixture was collected into the centrifuge tubes after boiling. The colour of the extract was pale brown and centrifuged the aqueous extract at $12,000 \times g$ for $10 \mathrm{~min}$. The supernatant was stored at $4{ }^{\circ} \mathrm{C}$ until further usage. 


\subsection{Biogenesis of AgNPs}

Aqueous solution of $1 \mathrm{mM}$ of $\mathrm{AgNO}_{3}$ was prepared in MilliQ-water. In actual experiments, the individual leaf extracts of $5 \mathrm{~mL}$ were added to $95 \mathrm{~mL}$ of $1 \mathrm{mM} \mathrm{AgNO}_{3}$ solution for the reduction of $\mathrm{Ag}^{+}$ions at $45^{\circ} \mathrm{C}$ in a constant shaking at $500 \mathrm{rpm}$ in orbital shaking incubator for $24 \mathrm{~h}$. The formation of AgNPs was analyzed by UV-Vis absorption spectrophotometer with a resolution of $1 \mathrm{~nm}$.

\subsection{Characterization of AgNPs}

The UV-Vis spectra of AgNPs synthesized by plant extracts of $A$. racemosus and S. interrupta was carried out between 200 and $800 \mathrm{~nm}$ using UV-Vis double-beam spectrometer (Spectra MAX; Molecular Devices; supported by SoftMax Pro-5.4) at a scan speed of $480 \mathrm{~nm} / \mathrm{min}$ at room-temperature. After the confirmation of the synthesis, the colloidal solution of AgNPs was centrifuged at 10,000 rpm for $30 \mathrm{~min}$ and the obtained pellet was washed thrice with deionized water to remove unbound phytochemicals, debris and other components present in the solution and the AgNPs were dried by lyophilization to obtain a powder. This powder was stored at $4{ }^{\circ} \mathrm{C}$ for further characterization and biological studies. Fourier transform infrared (FTIR) spectrum of the dried powder of AgNPs in the form of $\mathrm{KBr}$ pellet was recorded on ThermoNicolet Nexus 670 spectrometer at a resolution of $4 \mathrm{~cm}^{-1}$ in the wave number region of $500-4000 \mathrm{~cm}^{-1}$. The crystalline structure of AgNPs was determined using X-ray diffraction (XRD) analysis. The XRD pattern of AgNPs was recorded on PANalytical Empyrean operated at a voltage of $40 \mathrm{kV}$ and current of $30 \mathrm{~mA}$ using CuKa radiation $\left(\lambda=1.5406 \mathrm{~A}^{\circ}\right)$. The diffractometer was controlled with data scan software using scan rate of $1.2^{\circ}$ per minute and scan range of $2 \theta=0^{\circ}-80^{\circ}$. Transmission electron microscope (TEM) analysis was done to determine the morphology and size of AgNPs. TEM (100 W infrared lamp JEOL JSM-2100F) was operated at an accelerating voltage of $200 \mathrm{kV}$ with maximum magnification ranging from $25,000 \times-450,000 \times$. The dried AgNPs powder was redispersed in deionized water and subjected to dynamic light scattering (DLS) to determine the zeta potential on a Zetasizer Nano ZS (Malvern Instruments Ltd., UK) instrument equipped with a He-Ne laser operating at $632.8 \mathrm{~nm}$ and a scattering detector at $173^{\circ}$. Polydispersity index (PDI) value of the AgNPs was also determined using DLS. Thermo gravimetric analysis (TGA) was carried out to determine the thermal stability of AgNPs. Heating profile of $10^{\circ} \mathrm{C} / \mathrm{min}$ was used for all the tests from room temperature to $700^{\circ} \mathrm{C}$. The concentration of silver ions in the colloidal solution of AgNPs was determined by inductively coupled plasma optical emission spectrometer (ICP-OES, IRIS Intrepid II XDL, Thermo Jarrel Ash, USA). The concentration was calculated by $\mathrm{AgNO}_{3}$ standard graphs (1-50 ppm) plotted based on ICP-OES analysis.

\subsection{Antibacterial activity of AgNPs}

Different test concentrations of crude extracts and biogenic AgNPs were screened for antibacterial activity by agar disk-diffusion method [35]. Further compare the antibacterial properties of AgNPs with their respective source plant leaf extracts. The Gram-positive (Bacillus subtilis (MTCC 441) and Micrococcus luteus (MTCC 106), and Gram-negative [Escherichia coli (MTCC 443), and Klebsiella pneumonia (MTCC 109)] bacterial pathogens were obtained from Microbial Type Culture Collection and Gene bank (MTCC, Chandigarh). Test solutions were prepared using double distilled water in a $10 \mathrm{~mL}$ test tubes marked with $\mathrm{a}, \mathrm{b}, \mathrm{c}$ and $\mathrm{d}$ separately. $100 \mu \mathrm{g}$ of crude extract was taken in Test tube ' $a$ ' and dissolved in $4 \mathrm{~mL}$ of water with a final concentration of $25 \mu \mathrm{g} / \mathrm{mL}$. $100 \mu \mathrm{g}$ of dried powder of AgNPs was taken in Test tube ' $b$ ' and dissolved in $4 \mathrm{~mL}$ of water with a final concentration of $25 \mu \mathrm{g} / \mathrm{mL}$. $40 \mu \mathrm{g}$ of standard drug (gentamycin) was taken in Test tube ' $c$ ' and dissolved in $4 \mathrm{~mL}$ of water with a final concentration of $10 \mu \mathrm{g} / \mathrm{mL}$. Test tube 'd' contains only double distilled water. Sterile paper disks $(0.7 \mathrm{~cm})$ were saturated with $25 \mu \mathrm{L}$ of each test solution and allowed to dry. For all the bacterial strains, overnight cultures were adjusted to an inoculum size of $1-2 \times 10^{-8} \mathrm{CFU} / \mathrm{mL}$. An aliquot $(0.2 \mathrm{~mL})$ of each inoculum was added to the molten Mueller-Hinton agar medium (HiMedia Limited) containing petriplates. Thereafter, the completely saturated disks were transferred onto the upper layer of the Mueller-Hinton agar medium inoculated with bacteria. Each petriplate contain four disks. One disk was impregnated plant extract, second disk was impregnated with AgNPs. Third disk was impregnated with standard drug gentamycin. Fourth disk contains only distilled water. Petriplates were incubated for $24 \mathrm{~h}$ in bacterial growth chamber to observe the growth inhibition. After incubation period of $24 \mathrm{~h}$ at $37^{\circ} \mathrm{C}$, antibacterial activity was evaluated by quantifying the zones of inhibition $(\mathrm{mm}$ ) of bacterial growth (mean of six replicates was considered).

\subsection{Anticancer activity of AgNPs}

Anticancer activity was evaluated using the MTT [3- $(4,5-$ dimethylthiazol-2-yl)-2, 5-diphenyl tetrazolium bromide] assay [36]. Anticancer activity of biogenic AgNPs was evaluated against four different cancer cell lines including human ovarian carcinoma (SKOV3), human prostate cancer (PC-3 and DU145) and human lung adenocarcinoma (A549). FDA approved drug molecule doxorubicin used as a positive control. Cells were seeded in each well 
containing $100 \mu \mathrm{L}$ of medium at a final density of $\left(2 \times 10^{4}\right.$ cells/well) at identical conditions. After overnight incubation, the test compounds (leaf extracts and biogenic AgNPs) were dissolved in one $\mathrm{mL}$ of media. The cells were treated with different concentrations of test compounds $(1-400 \mu \mathrm{g} / \mathrm{mL})$. After $24 \mathrm{~h}$ of incubation, $10 \mu \mathrm{L}$ of MTT $(5 \mathrm{mg} / \mathrm{mL}$ ) was added to each well and then the plates were incubated at $37^{\circ} \mathrm{C}$ in the dark for $4 \mathrm{~h}$. The formazan crystals formed were dissolved in DMSO (100 $\mu \mathrm{L} /$ well) and the reduction of MTT was quantified by absorbance at $570 \mathrm{~nm}$ in a spectrophotometer (Spectra MAX M2e; Molecular Devices; supported by SoftMax Pro-5.4). The data was subjected to linear regression analysis and the regression lines were plotted for the best straight-line fit. The $\mathrm{IC}_{50}$ (concentration that inhibit $50 \%$ of cell viability) values were calculated using the respective regression equation.

\subsubsection{Study of morphological changes of cells}

Morphological changes of cancer cells were observed after $24 \mathrm{~h}$ of treatment with $\mathrm{IC}_{50}$ concentrations of biogenic AgNPs (SI-AgNPs and AR-AgNPs) Morphological changes such as cell shrinkage, warping of cells, membrane blebbing and formation of apoptotic bodies were studied using phase contrast microscopy (Optika, Italy) and fluorescence microscopy $[37,38]$.

\subsubsection{Acridine orange-Ethidium bromide staining assay}

Apoptotic changes after $24 \mathrm{~h}$ of treatment were studied by Acridine orange-Ethidium bromide (AO-EtBr) staining assay [39]. This assay is based on the principle that the live cells will be permeable to acridine orange but not to ethidium bromide. Hence live cells will be appeared in green. While dead cells will be permeable to both acridine orange and ethidium bromide, and dead cells will be appeared in red. Briefly, $95 \mu \mathrm{L}$ of $24 \mathrm{~h}$ treated cell suspension was added to $5 \mu \mathrm{L}$ of dye mixture at a concentration of $100 \mu \mathrm{g} /$ $\mathrm{mL}$. Then cells were washed with PBS thoroughly. After staining, cells were visualized immediately under a blue filter of fluorescence microscopy.

\subsubsection{Hoechst staining assay}

Nuclei of apoptotic cells showed very condensed chromatin. Hoechst 33,342 staining was used to detect the apoptotic nuclei [40]. Hoechst 33,342, a bis-benzimide dye binds AT-rich (Adenosine/thymidine) regions in the minor grove of ds DNA and emits very brightly. Normal cells containing loose chromatin shows moderate staining. After $24 \mathrm{~h}$ of treatment, cells were centrifuged and the pellet washed with PBS, and fixed the cells in $70 \%$ ethanol for $2 \mathrm{~h}$. Then the cells were stained with $10 \mu \mathrm{L}$ of Hoechst 33,342 solution ( $100 \mu \mathrm{g} / \mathrm{mL}$ concentration). Then centrifuged the cells to remove the dye and the cells were washed finally with PBS. Nuclear morphology changes were visualized under fluorescence microscopy using excitation wavelengths between 330 and $380 \mathrm{~nm}$.

\subsubsection{Cell migration inhibition assay}

To study the cell migration and inhibition, an in vitro wound healing assay or scratch assay is performed [41]. In this assay cells were seeded into a 24-well culture dish until $90 \%$ confluent. Then the cells were maintained in serum-free medium for $12 \mathrm{~h}$. The monolayers were carefully scratched using a $200 \mu \mathrm{L}$ pipette tip. The cellular debris was subsequently removed by washing with PBS, and the cells were incubated in serum free medium containing $\mathrm{IC}_{50}$ concentrations of SI-AgNPs and AR-AgNPs and without AgNPs for $24 \mathrm{~h}$. The migrated cells were fixed in cold $75 \%$ methanol for 30 min and washed thrice with PBS. The cultures were photographed at 0 and $24 \mathrm{~h}$ to monitor the migration of cells into the wounded area.
Fig. 1 UV-Vis absorption spectra at $24 \mathrm{~h}$ of newly synthesized AgNPs using leaf extracts of a $A$. racemosus and b S. interrupta
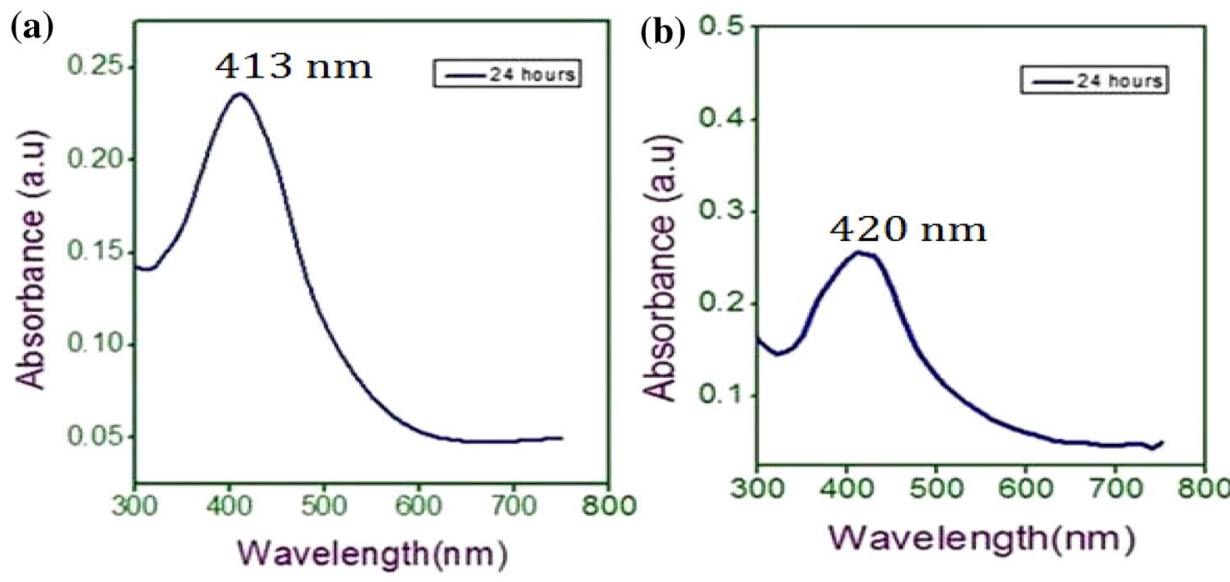


\subsection{Software tools and statistical analysis}

In this study we have used Microsoft-Excel 2007 for equations and Microsoft-Word 2007 for symbols. The graphs were drawn using Prism 7.0 software. The peaks related to UV-Vis, FTIR, TGA and XRD were drawn and interpreted using Origin Pro 8.5 software. Antibacterial activity data was represented as mean of six replicates. Anticancer activity data was represented as mean \pm SE of three independent experiments.

\section{Results and discussion}

\subsection{Biogenesis of AgNPs using plant extracts}

Crude aqueous leaf extracts of individual plants were prepared and the supernatants were stored at $4{ }^{\circ} \mathrm{C}$. This extracts act as reducing and capping agents for the synthesis and stabilization of AgNPs. Initially, synthesis of AgNPs was detected by colour change of reaction solutions (containing plant leaf extract and $\mathrm{AgNO}_{3}$ ) from light yellow colour to dark brown. Further they were analyzed by UV-Vis, TEM, XRD, DLS, TGA, ICP-OES and FTIR spectroscopic techniques. Furthermore, the synthesized AgNPs were evaluated for biological properties including antimicrobial and anticancer activities.

\subsection{UV-Vis analysis of biogenic AgNPs}

The colloidal solution of AgNPs synthesized from leaf extracts of $A$. racemosus and S. interrupta exhibited maximum absorption between 410 and $430 \mathrm{~nm}$ corresponding to the localized surface plasmon resonance (SPR) of AgNPs. The absorption spectra of AgNPs synthesized using two plant leaf extracts for $24 \mathrm{~h}$ at $45^{\circ} \mathrm{C}$ are presented in Fig. 1 . Thus the absorption spectra indicate the formation of ARAgNPs (A. racemosus leaf mediated AgNPs) and SI-AgNPs (S. interrupta leaf mediated AgNPs). AR-AgNPs showed maximum absorption at $413 \mathrm{~nm}$ and SI-AgNPs showed maximum absorption at $420 \mathrm{~nm}$. It is reported earlier that absorbance around $400-430 \mathrm{~nm}$ is a characteristic feature of these noble metal nanoparticles $[42,43]$. These biogenic AgNPs were stable for 6 months without shifting
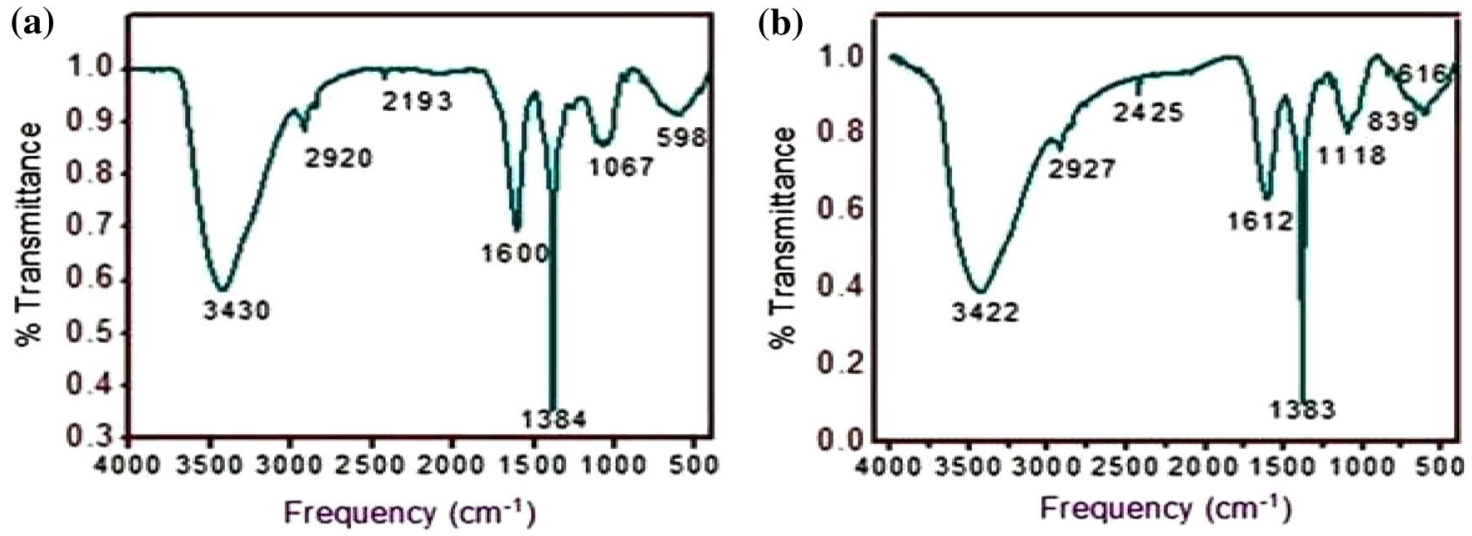

Fig. 2 FTIR spectra of a AR-AgNPs and $\mathbf{b}$ SI-AgNPs

Fig. 3 XRD pattern of a ARAgNPs and $\mathbf{b}$ SI-AgNPs
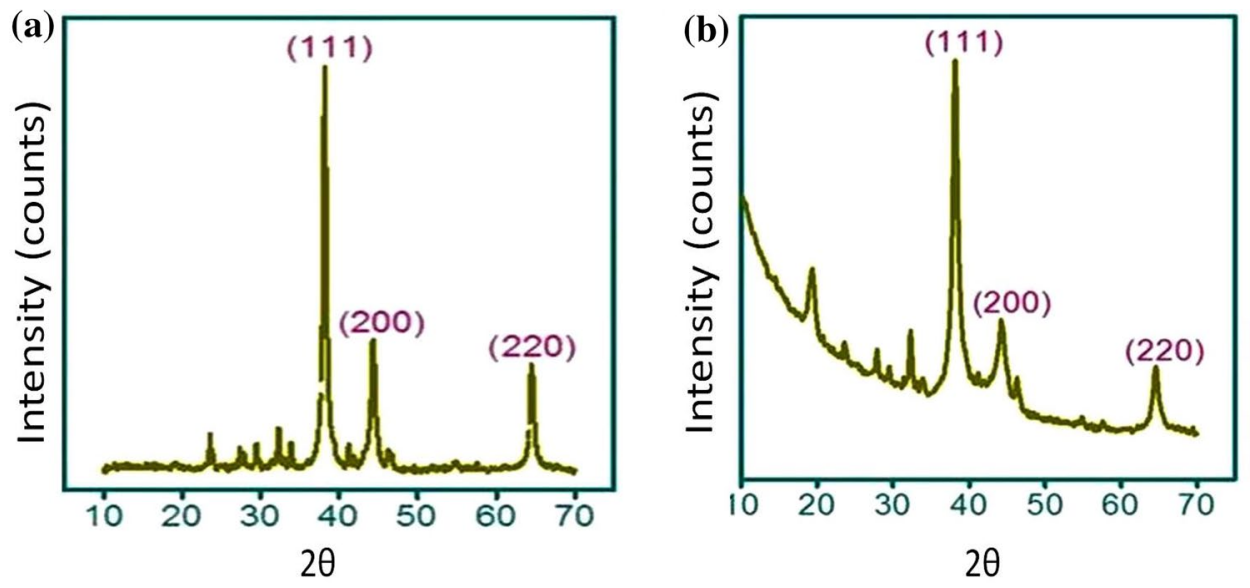
the absorption (SPR) peak. This suggests that the phytochemicals present in this medicinal plant leaf extracts also act as capping agents which impart stabilization to AgNPs.

\subsection{FTIR analysis of biogenic AgNPs}

FTIR analysis was carried out to determine the functional groups involved in the synthesis and stabilization of AgNPs (Fig. 2). FTIR spectrum of AR-AgNPs (Fig. 2a) showed peaks at 598, 1067, 1384, 1600, 2193, 2920 and $3430 \mathrm{~cm}^{-1}$. FTIR spectrum of SI-AgNPs (Fig. 2b) showed peaks at 616, 839, $1118,1383,1612,2425,2927$ and $3422 \mathrm{~cm}^{-1}$. The peaks at 3422 and $3430 \mathrm{~cm}^{-1}$ were corresponding to $\mathrm{O}-\mathrm{H}$ group of alcohols/phenols [26]. The peaks at 2920 and $2927 \mathrm{~cm}^{-1}$ were corresponding to asymmetric $\mathrm{C}-\mathrm{H}$ stretching vibrations of aromatic compounds such as flavonoids and phenols. This indicates that phenolic compounds of plants mainly involved in the reduction of silver ions into AgNPs. The peaks at 1600 and $1612 \mathrm{~cm}^{-1}$ were corresponding to
amide-II linkage of the proteins [28]. The peaks at 1383 and $1384 \mathrm{~cm}^{-1}$ were corresponding to $\mathrm{C}-\mathrm{N}$ stretching vibrations of aromatic amines. The peaks at 1067 and 1118 were responsible for $\mathrm{C}-\mathrm{O}$ stretching vibrations of phenolic acids/flavonoids/proteins [27]. This indicates that proteins of plant leaf extracts could be involved in the capping of AgNPs. The capping gives stability by preventing them from agglomeration. Further these proteins (involved in capping) and polyphenols and flavonoids (involved in bioreduction) impart biological activities to AgNPs. Thus the results of FTIR studies clearly indicated the presence of

Table 1 Zeta potential and polydispersity index (PDI) of biogenic AgNPs synthesized in the present study

\begin{tabular}{lll}
\hline AgNPs & $\begin{array}{l}\text { Zeta poten- } \\
\text { tial }(\mathrm{mV})\end{array}$ & PDI \\
\hline AR-AgNPs & -18.6 & 0.4 \\
Sl-AgNPs & -28.9 & 0.3 \\
\hline
\end{tabular}
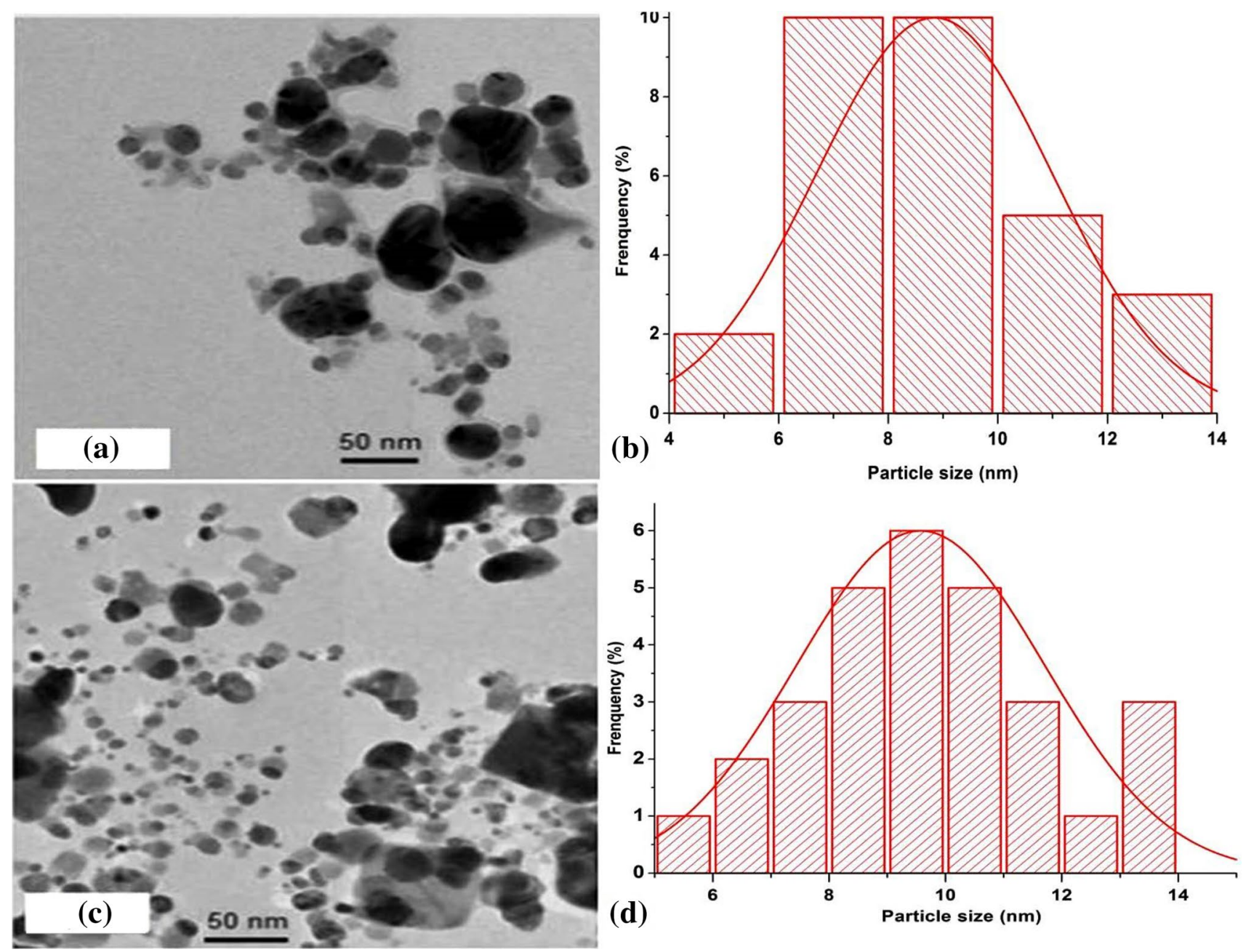

Fig. 4 TEM image AR-AgNPs (a) and corresponding histogram (b); TEM image of SI-AgNPs (c) and corresponding histogram (d) 
different phytochemicals involved in the bioreduction of $\mathrm{Ag}^{+}$ions into AgNPs as well as capping of AgNPs.

\subsection{XRD analysis of biogenic AgNPs}

The crystalline nature of biogenic AgNPs synthesized using two different plant extracts was confirmed by XRD analysis (Fig. 3). The XRD spectrum of AR-AgNPs showed three diffraction peaks at $38.17^{\circ}, 44.22^{\circ}$, and $64.56^{\circ}$ which are corresponding to (111), (200) and (220) planes respectively of FCC structure of AR-AgNPs. Further XRD pattern of SI-AgNPs showed Braggs's diffraction peaks at $38.16^{\circ}$, $44.43^{\circ}$ and $64.61^{\circ}$ corresponding to the planes (111) (200) and (220) of the FCC structure respectively. The diffraction peaks of AR-AgNPs and SI-AgNPs were consistent with the standard database files of JCPDS (card No 04-0783), suggesting that the synthesized AgNPs were of pure crystalline nature with FCC structure. The XRD spectra obtained from the AgNPs synthesized using two different plant extracts (A. racemosus, and S. interrupta) confirmed that they were pure crystalline in nature.

\subsection{TEM and DLS analysis of biogenic AgNPs}

TEM analysis of biogenic AgNPs including AR-AgNPs and SI-AgNPs was carried out to reveal their size and morphology. TEM analysis showed that AR-AgNPs, and SI-AgNPs are spherical in shape (Fig. 4a-d). The particle size distribution clearly revealed that AR-AgNPs are $5-15 \mathrm{~nm}$ in size with maximum distribution around $8-12 \mathrm{~nm}$ and SI-AgNPs are $5-14 \mathrm{~nm}$ in size with maximum distribution of $6-10 \mathrm{~nm}$. TEM results depicted that biogenic AgNPs are monodispersed, spherical and non-aggregated. Polydispersion index (PDI) values (Table 1) calculated by DLS technique further supports the monodispersion of biogenic AgNPs.
Table 2 Antibacterial activities of different plant leaf extracts used in the present study

\begin{tabular}{lccccc}
\hline Plant extracts & \multicolumn{2}{l}{ Gram-positive } & & \multicolumn{2}{c}{ Gram-negative } \\
\cline { 2 - 3 } \cline { 5 - 6 } & B. subtilis & M. luteus & & E. coli & K. pneumoniae \\
\hline S. interrupta & 4.6 & 5.3 & & 4.6 & 6.3 \\
A. racemosus & 5.3 & 5.3 & & 4.8 & 5.3 \\
Stand drug & 16.8 & 17.1 & & 18.2 & 17.3 \\
\hline
\end{tabular}

Data presented as the mean values of six replicates from two individual experiments

In this study, PDI values of AR-AgNPs and SI-AgNPs were found to be 0.5 and 0.3 respectively. Thus the PDI values of biogenic AgNPs were found to be below 0.7 indicating a narrow size distribution of the biogenic AgNPs. TEM results and PDI values indicated that SI-AgNPs are small in size followed by AR-AgNPs.

Zeta potential is one of the important parameter for determining the stability of the AgNPs. DLS analysis revealed the zeta potential values of the biogenic AgNPs. Zeta potential values (Table 1) of AR-AgNPs and SI-AgNPs were respectively found to be -18.6 and $-28.9 \mathrm{mV}$. The high negative zeta potential values generate high repulsive forces which prevent agglomeration. It indicates that the biogenic AgNPs were long term stable without agglomeration. Based on the zeta potential value, we could say that SI-AgNPs were more stable followed by ARAgNPs. In general, AgNPs were reported to be more stable at high negative zeta potential values.

\subsection{Thermogravimetric analysis of biogenic AgNPs}

TGA analysis was conducted in order to understand the thermal stability of the AR-AgNPs and SI-AgNPs. TGA plot
Fig. 5 The TGA plot of a ARAgNPs and $\mathbf{b}$ SI-AgNPs (a)

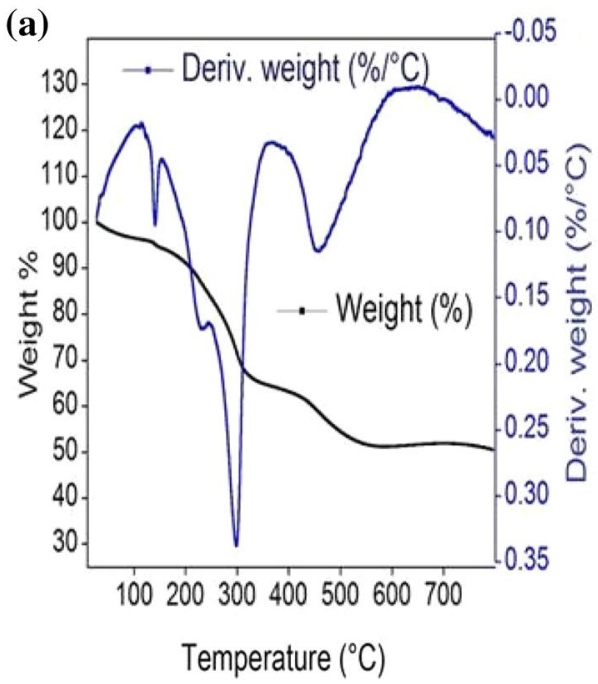

(b)

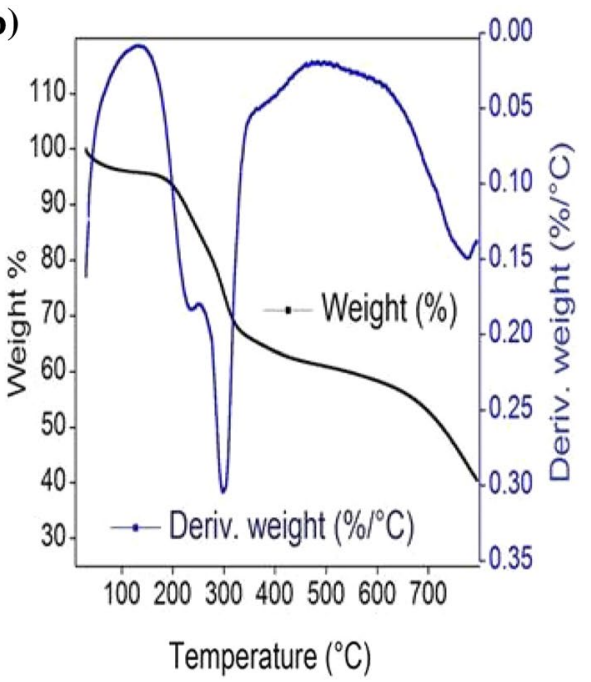


of the AR-AgNPs (Fig. 5a) exhibited three major weight losses at $230.35,300.76$, and $458.61{ }^{\circ} \mathrm{C}$. The observed weight loss might be due to desorption of phytochemicals/bioorganic compounds capped around AgNPS. The differential thermal analysis of SI-AgNPs (Fig. 5b) revealed that maximum weight loss of $36.15 \%$ was taken place at $220-300^{\circ} \mathrm{C}$. TGA results supported that phytochemicals of plant extracts act as conjugated molecules on the surface of the AgNPs and impart stability against temperature variations. FTIR spectra also revealed that phytochemicals of plant extracts act as capping agents and give stability to the AgNPs. In this study, DLS results (high negative zeta potential) also support the stability of AgNPs.

\subsection{ICP-OES analysis of biogenic AgNPs}

The ICP-OES technique is used to quantify the metal content based on the emission of photons from atoms or ions that have been excited in a radio frequency discharge. ARAgNPs showed high concentration of silver $(9.26 \mu \mathrm{g} / \mathrm{mL})$ followed by SI-AgNPs $(6.14 \mu \mathrm{g} / \mathrm{mL})$.

Based on the spectroscopic characterization, it is revealed that biogenic AgNPs were FCC crystalline in nature, spherical in shape and monodispersed. But the synthesized biogenic AgNPs were differing in their size and zeta potential measurements. SI-AgNPs were found to be very small (5-30 $\mathrm{nm}$ in size) compared to AR-AgNPs (10-50 nm). Further Sl-AgNPs were found to show high

Table 3 Antibacterial activities of biogenic AgNPs synthesized in the present study

\begin{tabular}{lccrrr}
\hline AgNPs & \multicolumn{2}{l}{ Gram-positive } & & \multicolumn{2}{l}{ Gram-negative } \\
\cline { 2 - 3 } \cline { 5 - 6 } \cline { 5 - 6 } & B. subtilis & M. luteus & & E.coli & K.pneumoniae \\
\hline SI-AgNPs & 9.8 & 9.1 & & 11.8 & 10.5 \\
AR-AgNPs & 9.6 & 8.0 & & 8.3 & 9.5 \\
Stand drug & 16.8 & 17.1 & & 18.2 & 17.3 \\
\hline
\end{tabular}

Data presented as the mean values of six replicates from two individual experiments negative zeta potential $(-28.9 \mathrm{mV})$ followed by AR-AgNPs $(-18.6 \mathrm{mV})$.

\subsection{Antibacterial activity of biogenic AgNPs}

Plant aqueous crude extracts were prepared using milli$Q$ water and evaluated for antibacterial activities against different Gram-positive (B. subtilis and M. luteus) and Gram-negative (E. coli and K. pneumoniae) bacteria. All the extracts exhibited very well bactericidal activities at 50-100 $\mu \mathrm{g} /$ disk. To identify the potent bioactive extracts, a low concentration of $25 \mu \mathrm{g} /$ disk was fixed. The inhibitory zone developed by the individual plant leaf extracts against each tested bacteria was measured and recorded after $24 \mathrm{~h}$. The mean values of six replicates from two individual experiments are presented in Table 2. A. racemosus leaf extract showed effective antibacterial activity against all the tested bacteria but maximum against $K$. pneumoniae $(5.3 \mathrm{~mm})$. Thus the leaf extracts showed maximum antibacterial activity against $K$. pneumoniae. It is evident from the results that all the extracts produced significant zone of inhibition against all the test bacteria. Antibacterial activities of biogenic AgNPs ( $25 \mu \mathrm{g} / \mathrm{disc}$ ) were evaluated against the same test strains of Gram-positive ( $M$. luteus and B. subtilis) and Gram-negative bacteria ( $E$. coli and $K$. pneumoniae) represented in Table 3. SI-AgNPs showed maximum antibacterial activity against $E$. coli (11.8 mm), followed by K. pneumoniae (10.5 mm), B. subtilis $(9.8 \mathrm{~mm})$ and $M$. luteus $(9.1 \mathrm{~mm})$. Whereas $S$. interrupta extract showed highest antibacterial activity against $K$. pneumoniae $(6.3 \mathrm{~mm})$ followed by M. luteus $(5.3 \mathrm{~mm}), B$. subtilis and E. coli $(4.6 \mathrm{~mm})$. SI-AgNPs showed 1.8-2.3 fold enhanced antibacterial activity compared to leaf extract of S. interrupta. AR- AgNPs exhibited effective inhibitory activity against $B$. subtilis $(9.6 \mathrm{~mm}), K$. pneumoniae $(9.5 \mathrm{~mm})$, E. coli $(8.3 \mathrm{~mm})$ and M. luteus $(8.0 \mathrm{~mm})$. A. racemosus leaf extract also showed effective antibacterial activity against all the tested bacteria including $K$. pneumoniae $(5.3 \mathrm{~mm}$ ) followed by M. luteus $(5.3 \mathrm{~mm})$, B. subtilis $(5.3 \mathrm{~mm})$ and E. coli (4.8 mm). AR-AgNPs exhibited 1.5-1.8 fold
Fig. 6 MTT assay results confirming the in vitro cytotoxicity effects of a $A$. racemosus and b $S$. interrupta leaf extracts against different cancer cell lines. Data represented as mean \pm SE of three independent experiments

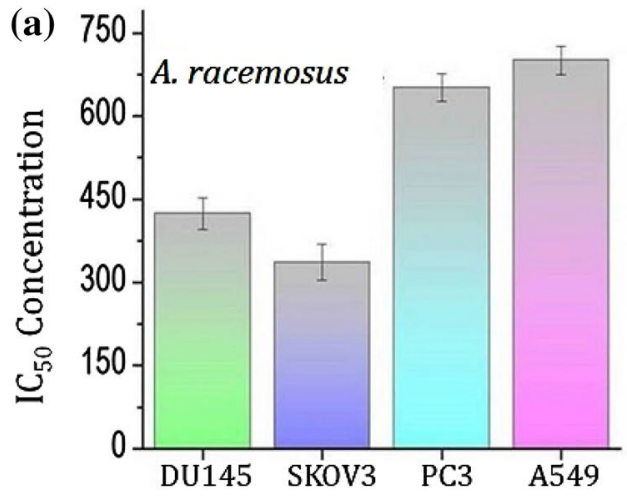

(b)

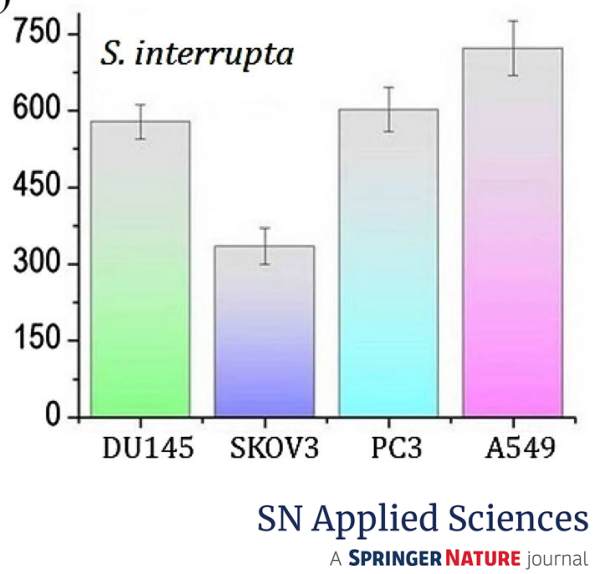


highest antibacterial activities compared to leaf extract of $A$. racemosus. Thus biogenic AgNPs showed 1.5-2.5 fold enhanced antibacterial activity compared with their respective source plant leaf extract. SI-AgNPs were found to be strong antibacterial agents compared to AR-AgNPs and SI-AgNPs. In this study among all the tested bacteria, K. pneumonia is more susceptible to biogenic AgNPs. The difference in the susceptibility might be due to difference in their nature and composition of cell membrane as well as the interaction of AgNPs with major bacterial proteins.

Due to their antibacterial nature, AgNPs have been used in the preparation of medical kits, diagnostic kits, and other hospital accessories. Further formulations of nanosilver combined with drugs showed inhibition against multidrug resistant bacteria [44]. Formulations of nanosilver combined with drugs showed synergistic effect against microbial infections. Hence these formulations have been used for the preparations of wound dressings, wound healing ointments, and antiseptic liquids. Due to their antimicrobial nature AgNPs were also used in the preparation of water purifiers. Owing to their antimicrobial and catalytic properties, AgNPs have been used for the removal of textile dyes, microbial contaminants and other toxic contaminants from the water [45].

\subsection{Anticancer activity studies}

\subsubsection{Cytotoxic effects of AgNPs}

Leaf aqueous extracts of $A$. racemosus and S. interrupta were evaluated for their cytotoxic properties using MTT assay on four different human cancerous cell lines, i.e., DU145, SKOV3, PC-3 and A549 (Fig. 6). Aqueous extracts of $A$. racemosus, and $S$. interrupta shown very less activity even at very high concentrations against all the cell lines. The $I C_{50}$ values of $A$. racemosus leaf extract against DU145, SKOV3, PC-3 and A549 cell lines were respectively found to be $424.16 \pm 28.84 \mu \mathrm{g} / \mathrm{mL}, 336.66 \pm 32.1 \mu \mathrm{g} / \mathrm{mL}$, $652.01 \pm 24.95 \mu \mathrm{g} / \mathrm{mL}$, and $701.14 \pm 25.43 \mu \mathrm{g} / \mathrm{mL}$. The
$\mathrm{IC}_{50}$ values of $S$. interrupta leaf extract against DU145, SKOV3, PC-3 and A549 cell lines were respectively found to be $334.81 \pm 33.7 \mu \mathrm{g} / \mathrm{mL}, 602.47 \pm 35.12 \mu \mathrm{g} / \mathrm{mL}$, $722.69 \pm 42.81 \mu \mathrm{g} / \mathrm{mL}$, and $579.02 \pm 53.31 \mu \mathrm{g} / \mathrm{mL}$. The results revealed that all the leaf extracts showed maximum cytotoxicity against SKOV 3 cells compared to other cells. Thus SKOV 3 cells were found to be more susceptible compared to DU145, PC-3 and A549. The IC $\mathrm{I}_{50}$ values of $A$. racemosus and S. interrupta leaf extracts against SKOV3 cells were respectively found to be $336.66 \pm 32.1 \mu \mathrm{g} / \mathrm{mL}$ and $334.81 \pm 33.7 \mu \mathrm{g} / \mathrm{mL}$. The results revealed that aqueous leaf extracts showed moderate cytotoxicity against all the cell lines used in this study. The cytotoxicity could be due to flavonoids, polyphenols, proteins and other phytochemicals present in the aqueous leaf extract.

The cytotoxic activities of the biogenic AgNPs (ARAgNPs and SI-AgNPs) were evaluated against the cell lines including DU145, PC-3 SKOV3 and A549 (Fig. 7) Biogenic AgNPs exhibited cytotoxic activities in a concentration-dependent manner. AR-AgNPs exhibited effective cytotoxicity against SKOV3 cells $\left(\mathrm{IC}_{50}=207.1 \pm 28.9 \mu \mathrm{g} /\right.$ $\mathrm{mL})$ followed by DU145 $\left(\mathrm{IC}_{50}=286.75 \pm 30.4 \mu \mathrm{g} /\right.$ $\mathrm{mL}), A 549\left(\mathrm{IC}_{50}=291.37 \pm 30.4 \mu \mathrm{g} / \mathrm{mL}\right)$ and $\mathrm{PC} 3$ $\left(\mathrm{IC}_{50}=512.34 \pm 44.5 \mu \mathrm{g} / \mathrm{mL}\right)$ cells. The $\mathrm{IC}_{50}$ values of ARAgNPs against different cell lines were ranging from 200 to $513 \mu \mathrm{g} / \mathrm{mL}$. Whereas the $\mathrm{IC}_{50}$ values of $A$. racemosus leaf extract were ranging from 336 to $701 \mu \mathrm{g} / \mathrm{mL}$. Thus ARAgNPs showed to 2-3.5 fold more anticancer activity compared to pristine leaf extract, i.e., A. racemosus leaf extract. SI-AgNPs exhibited effective cytotoxicity against SKOV3 cells $\left(I_{50}=120.87 \pm 14.9 \mu \mathrm{g} / \mathrm{mL}\right)$ followed by DU145 $\left(I C_{50}=191.34 \pm 20.6 \mu \mathrm{g} / \mathrm{mL}\right), P C 3\left(I_{50}=235.06 \pm 30.24 \mu \mathrm{g} /\right.$ $\mathrm{mL})$ and $A 549\left(\mathrm{IC}_{50}=314.27 \pm 40.6 \mu \mathrm{g} / \mathrm{mL}\right)$ cells. The $\mathrm{IC}_{50}$ values of SI-AgNPs against different cell lines were ranging from 120 to $314 \mu \mathrm{g} / \mathrm{mL}$. Whereas the $I_{50}$ values of $S$. interrupta leaf extract were ranging from 330 to $725 \mu \mathrm{g} /$ $\mathrm{mL}$. Thus SI-AgNPs showed 3-3.5 fold more anticancer activity compared to pristine leaf extract, i.e., S. interrupta leaf extract. SI-AgNPs were found to be strong anticancer
Fig. 7 MTT assay results confirming the in vitro cytotoxicity effects of $\mathbf{a}$ AR-AgNPs and $\mathbf{b}$ SIAgNPs against different cancer cell lines. Data represented as mean \pm SE of three independent experiments

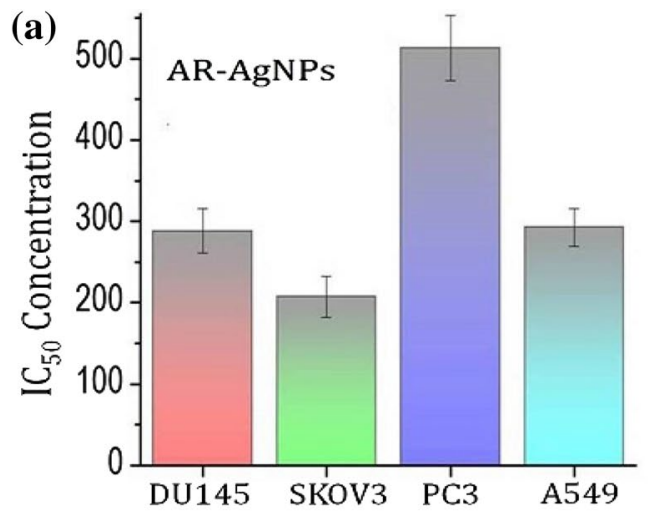

(b)

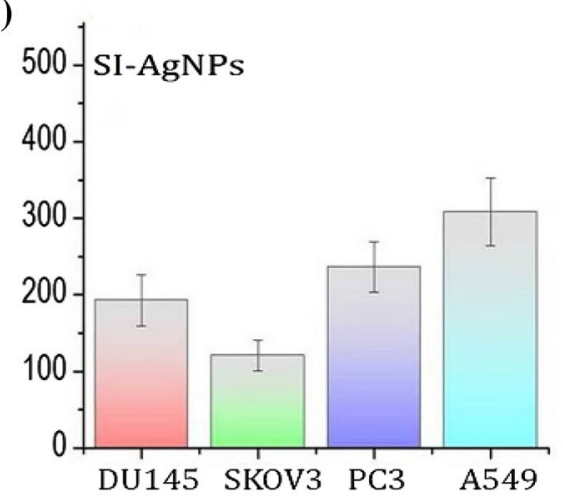


Fig. 8 Morphological changes of SKOV3 cells treated with biogenic AgNPs. Apoptotic effects of biogenic AgNPs were clearly observed in AO-EB and Hoechst staining. In AO-EB staining, viable cells appeared in green, late apoptotic cells appeared in orange shown nuclear fragmentation and loss of membrane integrity. Dead cells appeared in red colour. In Hoechst staining viable cells shown moderate staining while early apoptotic and dead cells appeared with bright fluorescence.Chormatin condensation (pyknosis) and nuclear fragmentation (karyorrhexix) were observed in early apoptotic cells

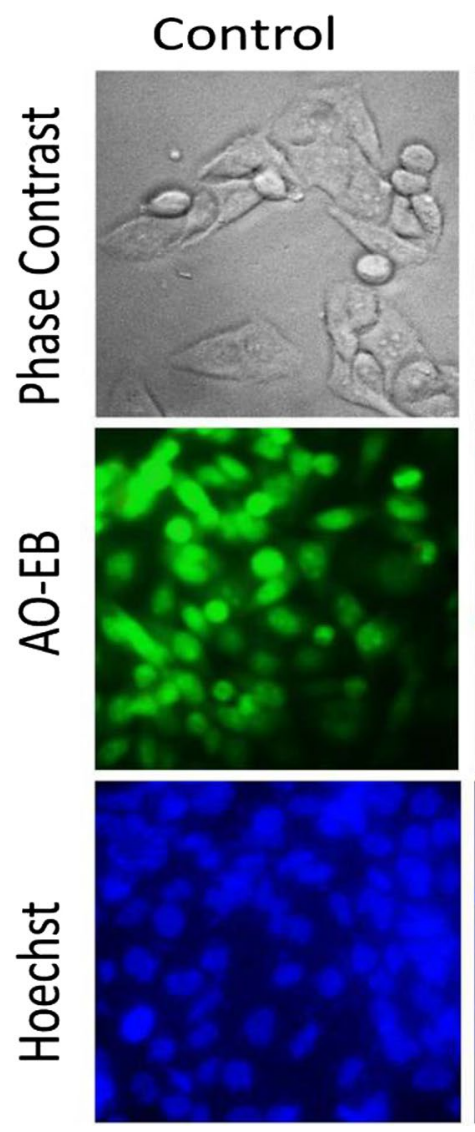

SI-AgNPs
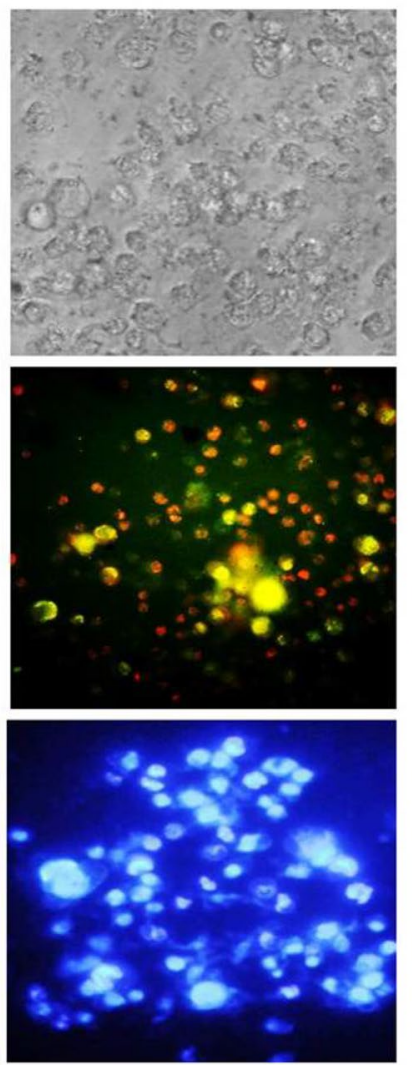

AR-AgNPs
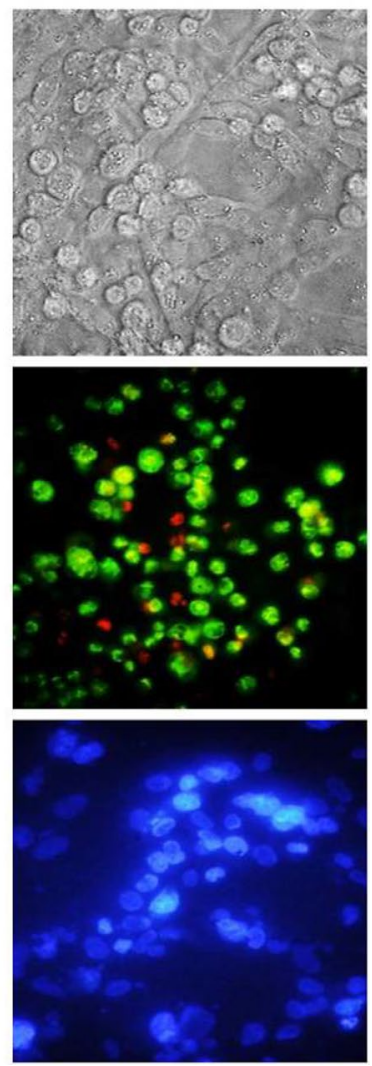

agents followed by AR-AgNPs. Sl-AgNPs exhibited 1-1.5 fold more cytotoxicity than AR-AgNPs. Further the biogenic AgNPs found to show strong inhibition against SKOV 3 cells. The $I_{50}$ values of AR-AgNPs and SI-AgNPs against SKOV3 cells were found to be $207.1 \pm 28.9$ and $120.87 \pm 14.9 \mu \mathrm{g} / \mathrm{mL}$ respectively. SKOV3 cells were found more susceptible to the biogenic AgNPs compared to other cell lines including DU145, PC3 and A549. The order of sensitivity against biogenic AgNPs among the cell lines were determined as SKOV3 > DU145 > PC-3 > A549. Further biocompatibility of the biogenic AgNPs was checked against normal $\mathrm{CHO}$ cells. Nevertheless, the biogenic AgNPs are 16-fold less toxic to $\mathrm{CHO}$ cells.

In this study biogenic AgNPs showed more cytotoxicity compared to their respective leaf extracts. SI-AgNPs found to show more cytotoxicity compared to AR-AgNPs. Among all the cell lines used in this study, SKOV3 cells were found to be more susceptible to AgNPs compared to other cell lines including DU145, PC-3 and A549. Biogenic AgNPs showed no cytotoxicity against normal $\mathrm{CHO}$ cells. Hence all the biogenic AgNPs were found to be cytotoxic against cancer cells and biocompatible towards normal cells.
Fig. 9 Cell migration inhibition of SKOV3 cells treated with biogenic AgNPs. The wounded gap of SKOV3 monolayers was completely healed with cells in control. SI-AgNPs clearly decreased the healing of wounded gap and $10-15 \%$ of wounded gap only was filled with cells. AR-AgNPs showed moderate cell migration inhibition and $60-70 \%$ of wound gap was healed with cells
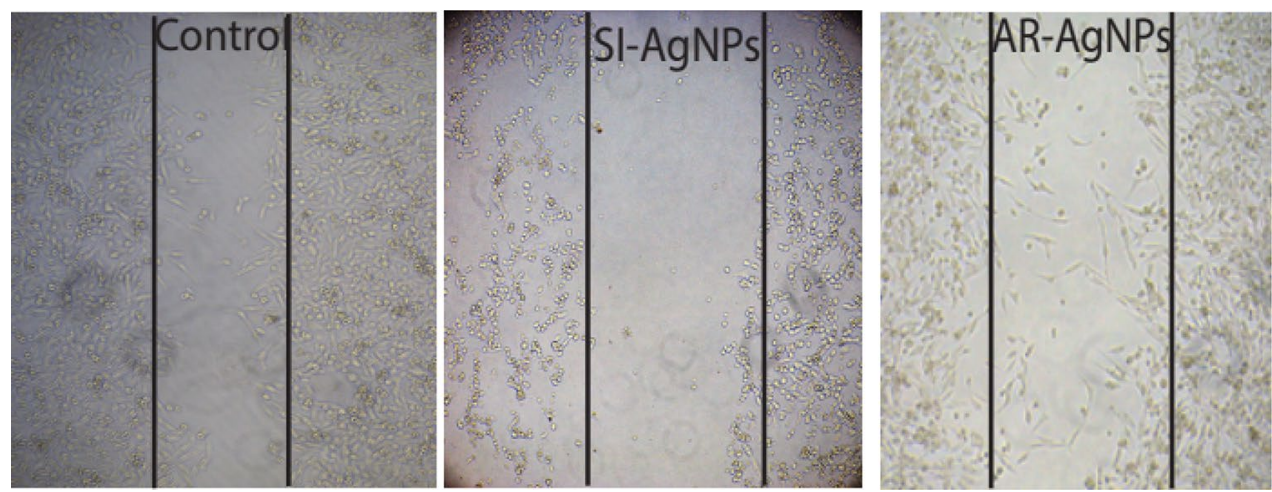

SN Applied Sciences a SPRINGer Nature journal 


\subsubsection{Study of morphological changes of cancer cells treated with AgNPs}

Effects of biogenic AgNPs on the most susceptible cell line SKOV3 were further studied by analysing morphological changes. Apoptotic features of SKOV 3 cells after $24 \mathrm{~h}$ of treatment with $\mathrm{IC}_{50}$ concentration of AgNPs were studied by phase contrast and fluorescence microscopy. General cell morphology of SKOV3 control cells (without treatment) under phase contrast and fluorescence microscopy were observed in control column. Cell morphology of SKOV3 cells after $24 \mathrm{~h}$ exposure to AgNPs clearly revealed the apoptotic changes (Fig. 8). In AO-EtBr staining, viable cells are permeable to acridine orange and they appeared

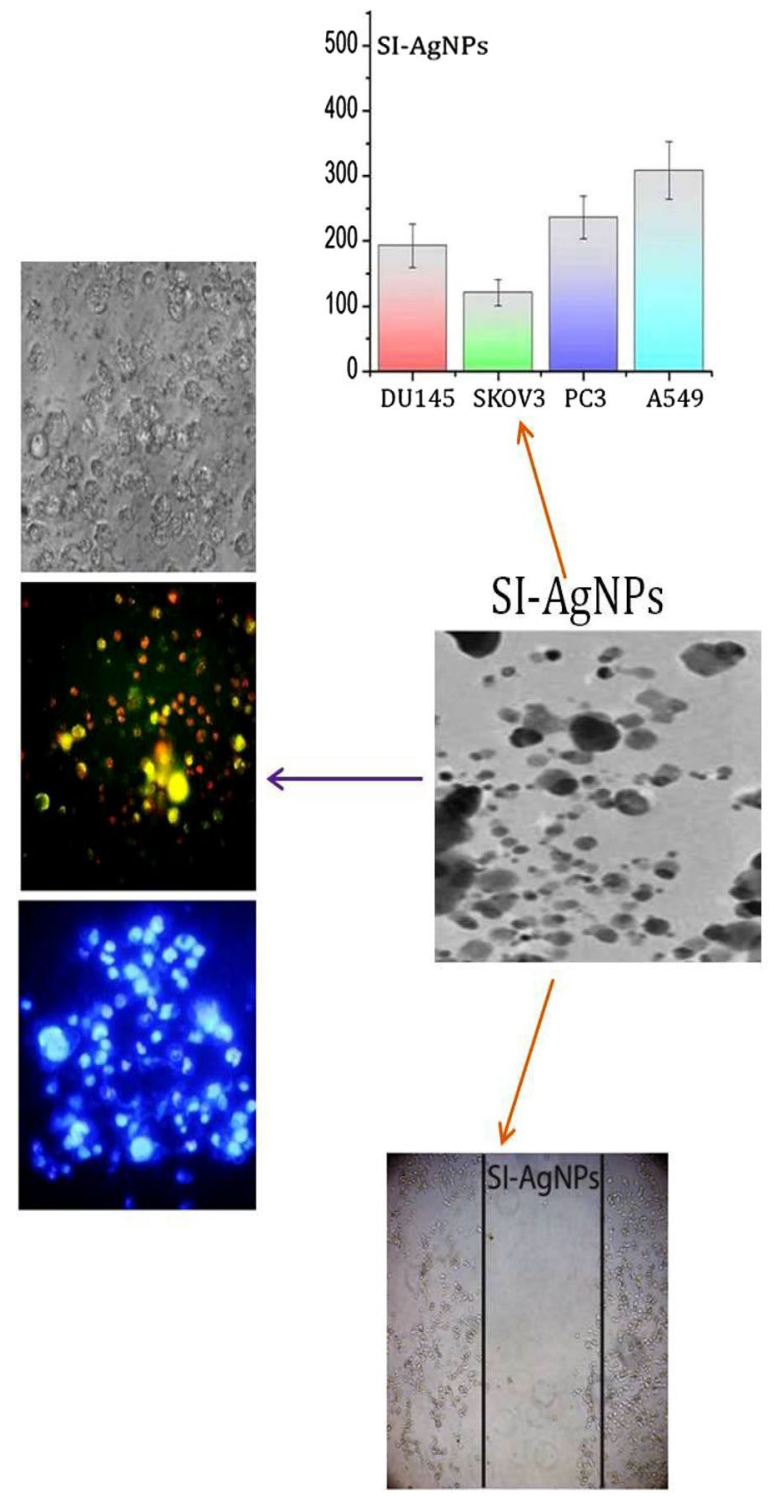

in green, late apoptotic cells emits orange fluorescence and they are characterized by cell membrane blebbing, cytoplasmic shrinkage, destructive fragmentation of nuclei (karyorrhexis), and irregular distribution of chromatin. While dead cells appeared in red. EtBr enters only through damaged membrane hence late apoptotic and dead cells emit orange/red fluorescence. In Hoechst staining, normal cells shown moderate staining. Early apoptotic cells had shown very bright appearance. Early apoptosis is characterized by cell shrinkage, rounding of cells, and breakdown of cytoskeleton followed by condensation of chromatin (pyknosis). AO-EtBr and Hoechst staining images clearly revealed that SI-AgNPs exhibited pronounced apoptotic effects compared to AR-AgNPs.

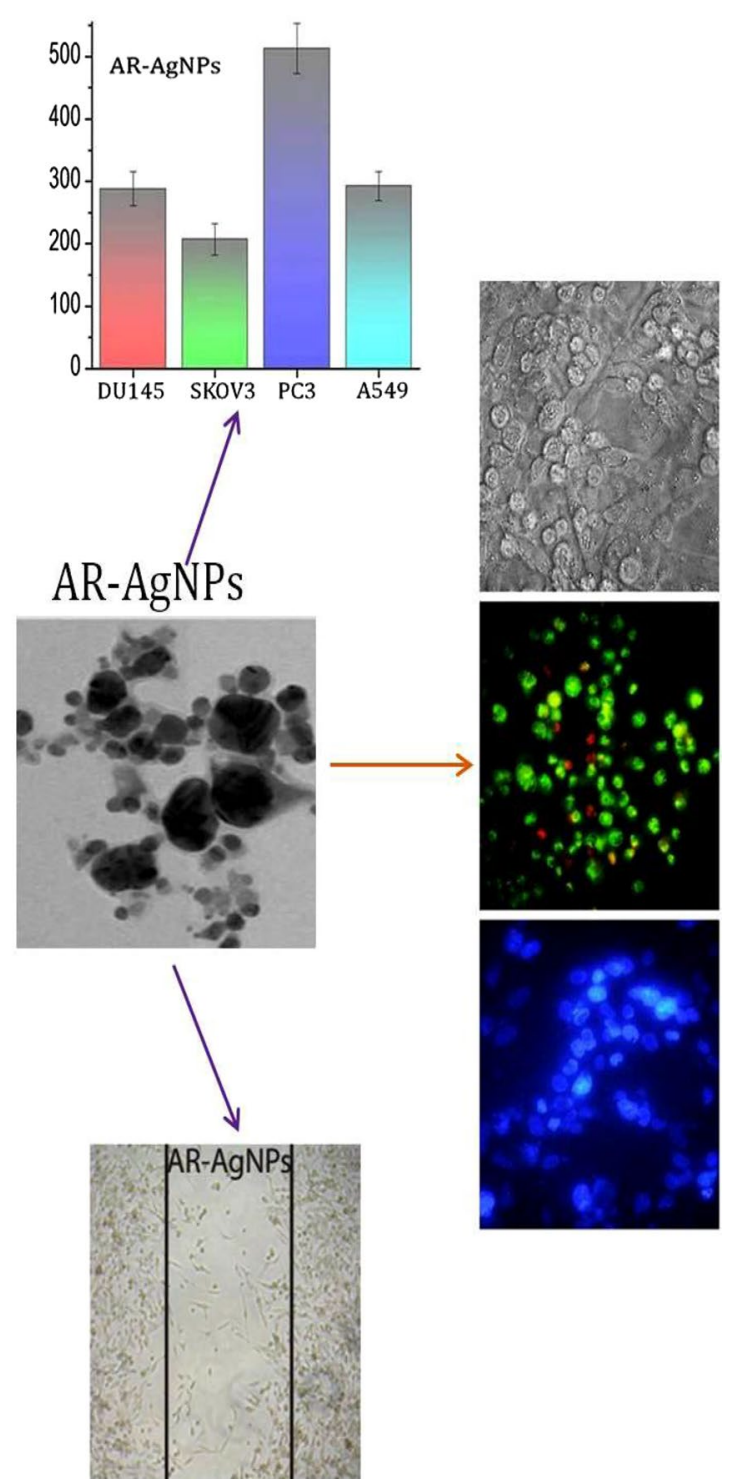

Fig. 10 Schematic representation of anticancer activity studies (MTT assay, light microscopy images, AO-EtBr staining, Hoechst staining, and cell migration inhibition) of SI-AgNPs and AR-AgNPs 
Table 4 Characteristic features and biological activities of biogenic AgNPs synthesized in the present study

\begin{tabular}{lll}
\hline & AR-AgNPs & SI-AgNPs \\
\hline Biosynthesis duration (h) & 24 & 24 \\
SPR peak (nm) & 413 & 420 \\
Morphology & Spherical & Spherical \\
Size (nm) & $10-50$ & $5-30$ \\
Crystal structure & FCC & FCC \\
Zeta potential (mV) & -18.6 & -28.9 \\
Antibacterial activity & Yes & Yes \\
& AR-AgNPs < SI-AgNPs & SI-AgNPs $>$ AR-AgNPs \\
& Highest against B. subtilis, followed by K. pneumoniae, E. & Highest against E. coli, followed by K. pneumoniae, B. \\
& coli and M. luteus & subtilis and M. luteus \\
Anticancer activity & Yes & Yes \\
& AR-AgNPs $<$ SI-AgNPs & SI-AgNPs $>$ AR-AgNPs \\
& Highest cytotoxicity against SKOV3 cells followed by & Highest cytotoxicity against SKOV3 cells followed by \\
& DU145 & DU145 \\
Biocompatibility & A549 and PC3 & PC3 and A549 \\
\hline
\end{tabular}

\subsubsection{Cell migration inhibition studies}

Cell migration plays a key role in the progression of cancer diseases. We assessed the effects of phytosynthesized AgNPs (SI-AgNPs and AR-AgNPs) on migration ability of SKOV 3 cells by wound healing/scratch assay. The results revealed that wound healing gaps are reduced clearly in control after $24 \mathrm{~h}$ (Fig. 9). Compared to control, phytosynthesized AgNPs reduced the closure rate of wounded area and they showed wound gaps even after $24 \mathrm{~h}$. $70 \%$ of wounded area is recovered in the presence of AR-AgNPs. But, SI-AgNPs showed pronounced inhibitory effect on the cell migration and only 10 to $15 \%$ of the wounded area is recovered. Thus SI-AgNPs found to show more cytotoxic effects followed by AR-AgNPs. The inhibition of cell migration might be attributed to the decreased expression levels of matrix metalloproteinases including MMP-2 and MMP-9.

Anticancer activity studies (MTT assay, light microscopy images, AO-EtBr staining, Hoechst staining, and cell migration inhibition) of SI-AgNPs and AR-AgNPs were represented as a schematic diagram (Fig. 10).

The spectroscopic characterization features and biological activities of AR-AgNPs and SI-AgNPs were clearly represented in Table 4.

\section{Conclusions}

In the present study we report the successful synthesis of clean, nontoxic and biocompatible AgNPs using two plant leaf extracts including $S$. interrupta and $A$. racemosus.
The biogenic AgNPs were spherical in shape, face centered cubic crystalline in nature. The biogenic AgNPs are monodispersed with PDI value less than 0.7. The biogenic AgNPs are long term stable without agglomeration and exhibiting high negative zeta potential. SI-AgNPs were found to show strong anticancer activity and good antibacterial activity. While AR-AgNPs were moderate in both antibacterial and anticancer activities. The biogenic AgNPs showed highest cytotoxicity against SKOV3 cells followed by DU145, PC3 and A549. The biogenic AgNPs were proved to be biocompatible by showing no toxicity to normal $\mathrm{CHO}$ cells. In this study SI-AgNPs were found to be very small and more stable compared to AR-AgNPs. Further SI-AgNPs showed more cytotoxicity compared to AR-AgNPs. Thus the present study clearly represented the characteristic features, antibacterial and anticancer activities of ARAgNPs and SI-AgNPs.

Authors' contributions All the work was done under the supervision of Dr. J. Venkateswara Rao and Murali Satyanarayana. N. Vasudeva Reddy carried out synthesis, characterization and manuscript preparation. Dr. Murali carried out characterization, anticancer activity and wound healing assay studies.

\section{Compliance with ethical standards}

Conflict of interest All the authors declared that they are no conflicts of interest.

Ethical statement No animals were used for the present study.

Consent for publication All the authors approved and consent for publication. 


\section{References}

1. Bhattacharya R, Mukherjee P (2008) Biological properties of naked metal nanoparticles. Adv Drug Deliv Rev 60:1289-1306

2. Singh J, Dutta T, Kim K, Rawat M, Pallabi S, Kumar P (2018) Green synthesis of metals and their oxide nanoparticles: applications for environmental remediation. J Nanobiotechnol 16:84

3. Verma DK, Hasan SH, Banik RM (2016) Photo-catalyzed and phyto-mediated rapid green synthesis of silver nanoparticles using herbal extract of Salvinia molesta and its antimicrobial efficacy. J Photochem Photobiol B Biol 155:51-59

4. Kelly KL, Coronado E, Zhao LL, Schatz GC (2003) The optical properties of metal nanoparticles: the influence of size shape and dielectric environment. J Phys Chem B 107:668-677

5. West JL, Halas NJ (2000) Applications of nanotechnology to biotechnology. Curr Opin Biotechnol 11:215

6. Fatima M, Hassan RYA, Silvana A (2017) Multifunctional nanotechnology-enabled sensors for rapid capture and detection of pathogens. Sensors (Basel) 17(9):2121

7. Po-Hsuan H, Chia-Yun C (2019) Insights for realizing ultrasensitive colorimetric detection of glucose based on carbon/silver core/shell nanodots. ACS Appl Bio Mater 2(6):2528-2538

8. Ping-Tsung H, Yu-Ning C, Kuan-Chung C, Shun-Huei W, ChingPing $L$ (2019) Confinement of silver nanoparticles in polystyrenes through molecular entanglements and their application for catalytic reduction of 4-nitrophenol. J Mater Chem A 7(36):20919-20925

9. Sunfengda $S$, Xiaojun $H$, Hongjie $L$, Jialin Z, Kwangnak K, Hongxia C (2018) Guests involved CB[8] capped silver nanoparticles as a means of electrochemical signal enhancement for sensitive detection of caspase-3. Sens Actuators B Chem 274:54-59

10. Neng $Y$, Tang BZ, Wen-Xiong W (2018) In vivo bioimaging of silver nanoparticle dissolution in the gut environment of zooplankton. ACS Nano 12:12212-12223

11. Parveen S, Misra R, Sahoo SK (2012) Nanoparticles: a boon to drug delivery therapeutics diagnostics and imaging. Nanomed Nanotechnol Biol Med 8(2):147-166

12. Behravan $M$, Hossein $P A$, Naghizadeh $A$, Ziaee $M$, Mahdavi $R$ Mirzapour A (2019) Facile green synthesis of silver nanoparticles using Berberis vulgaris leaf and root aqueous extract and its antibacterial activity. Int J Biol Macromol 124:148-154

13. Mukherjee $S$, Chowdhury D, Rajesh K, Patra S, Vinothkumar B, Manika PB, Sreedhar B, Patra CR (2014) Potential theranostics application of bio-Synthesized silver nanoparticles (4-in-1 System). Theranostics 4:316-335

14. Evanoff DD, Chumanov G (2004) Size-controlled synthesis of nanoparticles 1"silver-only" aqueous suspensions via hydrogen reduction. J Phys Chem B 108:13948-13956

15. Abbasi AR, Kalantary H, Yousefi M, Ramazani A, Morsali A (2012) Synthesis and characterization of Ag nanoparticles@polyethylene fibers under ultrasound irradiation. Ultrason Sonochem 19:853-857

16. Zhang Z, Patel RC, Kothari R, Johnson CP, Friberg SE, Aikens PA (2000) Stable silver clusters and nanoparticles prepared in polyacrylate and inverse micellar solutions. J Phys Chem 104:1176-1182

17. Pastoriza-Santos I, Liz-Marzán LM (1999) Formation and stabilization of silver nanoparticles through reduction by NN-dimethylformamide. Langmuir 15:948-951

18. Frattini A, Pellegri N, Nicastro D, deSanctis $O$ (2005) Preparation of amine coated silver nanoparticles using triethylenetetramine. Mater Chem Phys 94:148-152

19. Nasiriboroumand M, Montazer M, Barani H (2018) Preparation and characterization of biocompatible silver nanoparticles using pomegranate peel extract. J Photochem Photobiol B Biol 179:98-104

20. Vankar PS, Shukla D (2012) Biosynthesis of silver nanoparticles using lemon leaves extract and its applications for antimicrobial finish on fabric. Appl Nanosci 2(2):163-168

21. Hamedi S, Shojaosadati SA, Mohammadi A (2017) Evaluation of the catalytic antibacterial and anti-biofilm activities of the Convolvulus arvensis extract functionalized silver nanoparticles. J Photochem Photobiol B Biol 167:36-44

22. Iravani S (2011) Green synthesis of metal nanoparticles using plants. Green Chem 13:2638-2650

23. Das D, Ghosh R, Mandal P (2019) Biogenic synthesis of silver nanoparticles using S1 genotype of Morus alba leaf extract: characterization, antimicrobial and antioxidant potential assessment. SN Appl Sci 1:498

24. Thi T, Thuy T, Thi T, Hu V, Thi HN (2013) Biosynthesis of silver nanoparticles using Tithonia diversifolia leaf extract and their antimicrobial activity. Mater Lett 105:220-223

25. Hu D, Gu X, Si W, Qin W, Jiao J, Hao YF (2019) Biosynthesis of Silver nanoparticles using Bauhinia acuminate flower extract and their effect to promote osteogenesis of MSCs and improve meniscus injury healing. J Photochem Photobiol B Biol 197:111536

26. Anjum S, Abbasi BH (2016) Biomimetic synthesis of antimicrobial silver nanoparticles using in vitro-propagated plantlets of a medicinally important endangered species: Phlomis bracteosa. Int J Nanomed 11:1663-1675

27. Dubey SP, Lahtinen M, Sillanpää M (2010) Tansy fruit mediated greener synthesis of silver and gold nanoparticles. Process Biochem 45:1065-1071

28. Kantrao S, Venkataraman A (2014) Biosynthesis and characterization of stable silver nanoparticles using Ficus religiosa leaf extract: a mechanism perspective. J Clust Sci 25:1157-1171

29. Yang N, Li W-H (2013) Mango peel extract mediated novel route for synthesis of silver nanoparticles and antibacterial application of silver nanoparticles loaded onto non-woven fabrics. Ind crop Prod 48:81-88

30. Basu S, Maji P, Ganguly J (2016) Rapid green synthesis of silver nanoparticles by aqueous extract of seeds of Nyctanthes arbortristis. Appl Nanosci 6:1-5

31. Ananda AP, Krishnamurthy NB, Savitha KR, Nagendra BS (2019) Biogenic synthesis of silver nanoparticles using Priva cordifolia leaf extract (PC@AgNPs) a potent antioxidant, antibacterial and catalytic activity. SN Appl Sci 1:800

32. Umesh BJ, Vishwas AB (2013) Green synthesis of silver nanoparticles using Artocarpus heterophyllus Lam seed extract and its antibacterial activity. Ind crop Prod 46:132-137

33. Alok S, Jain SK, Verma A, Kumar M, Mahor A, Monika S (2013) Plant profile phytochemistry and pharmacology of Asparagus racemosus (Shatavari): a review. Asian Pac J Trop Dis 3:242-251

34. Manjula C, Ammani K (2012) Phytochemical analysis and pharmacological importance of Sophora interrupta leaves. Int J Res Pharm Biomed Sci 3:1798-1804

35. Bauer AW, Kirby WM, Sherris JC, Turck M (1966) Antibiotic susceptibility testing by a standardized single disk method. Am J Clin Pathol 45:493-496

36. Mosmann T (1983) Rapid Colorimetric assay for cellular growth and survival: application to proliferation and cytotoxicity assays. J Immunol Methods 65:55-63

37. Murali SB, Reddy NV, Latha D et al (2018) Potential anticancer activity of biogenic silver nanoparticles using leaf extract of Rhynchosia suaveolens: an insight into the mechanism. Artif Cells Nanomed Biotechnol 46:104-114. https://doi. org/10.1080/21691401.2017.1414824

38. Netala VR, Murali SB, Bobbu PL et al (2016) Biogenesis of silver nanoparticles using endophytic fungus Pestalotiopsis 
microspora and evaluation of their antioxidant and anticancer activities. Int J Nanomed 11:5683-5696

39. Shailaja KK, Amarante-Mendes GP, Finucane D, Brunner T, BossyWetzel E, Green DR (2006) Acridine orange/ethidium bromide (AO/EB) staining to detect apoptosis. Cold Spring Harb Protoc. https://doi.org/10.1101/pdb.prot4493

40. Lema C, Varela-Ramirez A, Renato JA (2011) Differential nuclear staining assay for high-throughput screening to identify cytotoxic compounds. Curr Cell Biochem 1:1-14

41. Rodriguez LG, Wu X, Guan JL (2005) Wound-healing assay. Methods Mol Biol 294:23-29

42. Mulvaney P (1996) Surface plasmon spectroscopy of nanosized metal particles. Langmuir 12:788-800

43. Wiley BJ, Im SH, Li ZY, Mclellan J, Siekkenen A, Xia Y (2006) Maneuvering the surface plasmon resonance of silver nanostructures through shape-controlled synthesis. J Phys Chem 110:15666-15675

44. Khatoon N, Alam H, Khan A, Raza K, Sardar M (2019) Ampicillin silver nanoformulations against multidrug resistant bacteria. Sci Rep 9:6848. https://doi.org/10.1038/s41598-019-43309-0

45. Khatoon N, Alam H, Manzoor N, Sardar M (2018) Removal of toxic contaminants from water by sustainable green synthesized non-toxic silver nanoparticles. IET Nanobiotechnol 12:1090-1096

Publisher's Note Springer Nature remains neutral with regard to jurisdictional claims in published maps and institutional affiliations. 